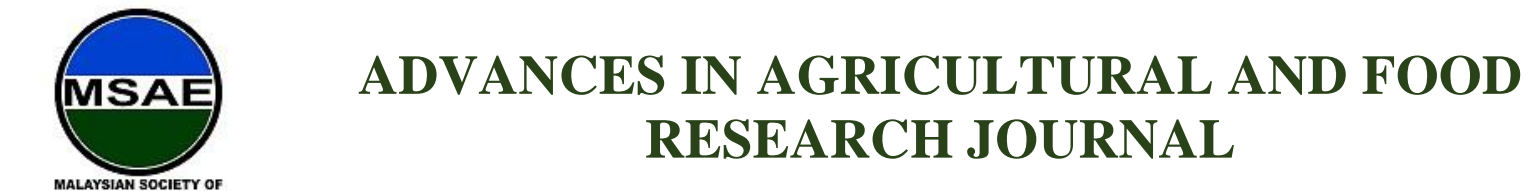

Original Research Article

\title{
Comparison of the Physical Properties between Malaysian and Thai Rice
}

Parichart Sathongpan ${ }^{1}$, Rosnah Shamsudin ${ }^{2 *}$, Jaturapatr Varith ${ }^{1}$, Nur Farhana Abd Rahman ${ }^{1,2}$

${ }^{1}$ Department of Food Engineering, Faculty of Engineering and Agro-Industry, Maejo University 63 SansaiPhrao Road, Nongharn, Sansai District, Chiang Mai, 50290 Thailand

${ }^{2}$ Department of Process and Food Engineering, Faculty of Engineering, Universiti Putra Malaysia, 43400 Serdang, Selangor, Malaysia,

*Corresponding author: Rosnah Shamsudin, Department of Process and Food Engineering, Faculty of Engineering, Universiti Putra Malaysia, 43400 Serdang, Selangor, Malaysia: rosnahs@upm.edu.my

\begin{abstract}
Rice is a staple food in the world market, especially in the Asian region. In each country, rice characteristics will differ in terms of shape, grade, and size. Thailand is one of the exporters in the global market rice among Asia South countries. Numerous studies have been done on different varieties of white and brown rice. However, research on physicochemical properties of different origin of white rice varieties is still limited, particularly between Malaysian and Thai rice. Therefore, it is essential to compare rice cultivars based on origin. This research aimed to evaluate the differences in physicochemical properties and improve Malaysian and Thai rice. One kilogram of Malaysian and Thai rice was processed into powder by way of grinding and then prepared for physicochemical measurement by sieving the produced rice powders with a size of $2 \mathrm{~mm}$ to get rid of foreign objects. The physical parameters measured were length, width, length/breadth ratio, thickness, density, grain shape, surface area, bulk density, actual density, porosity, sphericity, aspect ratio, thousand weight kernels angle of repose, colour ( $\left.\mathrm{L}, \mathrm{a}^{*}, \mathrm{~b}^{*}\right)$ and hardness. The results of the study showed no significant differences $(p>0.05)$ in terms of length, width, length/breadth ratio, actual density, porosity, sphericity, aspect ratio, angle of repose, Lightness (L) and $\mathrm{b}^{*}$. However, there is a significant variation $(p<0.05)$ between Malaysian and Thai rice in terms of thickness, surface area, bulk density, thousand weight kernels, colour $\left(\mathrm{a}^{*}\right)$, and hardness parameters. The evaluation of the quality of Malaysian and Thai rice can be a guide or reference for the grading and sorting processing sectors according to consumers' preferences, respectively.
\end{abstract}

Keywords: physical properties; rice; Malaysia cultivar; Thailand cultivar; angle of repose; hardness

Received: $5^{\text {th }}$ June 2020

Received in review form: $26^{\text {th }}$ November 2020 
Accepted: $20^{\text {th }}$ December 2020

Citation: Parichart S, Rosnah S, Jaturapatr V, et al. Comparison of the physical properties between Malaysian and Thai rice. Adv Agri Available Online: $15^{\text {th }}$ January 2021 Food Res J 2021; 2(1): a0000177. https://doi.org/10.36877/aafrj. a0000177

\section{Introduction}

Rice (Oryza sativa L.) is one of the leading food crops globally and is the staple food of approximately one-half of the world's population (Singh et al., 2003), consumed mainly in the form of whole grains. Rice has great diversity in its genetic background, grain shape, and cooking quality. The grain size and shape are among the first qualities that are considered in rice varieties for commercial production. They are primary factors in marketing, grading, and processing (Husain, 1984). The type of rice may affect properties such as grain size, shape, thousand-kernel weight, hardness, and density and eventually affect the final grain quality (Yadav et al., 2007). During cooking, rice properties are changed due to exposure to high temperatures; this is believed to result from more remarkable water migration during cooking (Saleh \& Meullenet, 2013). Aside from this, there are also external factors such as soaking time, cooking time, and water uptake before the cooking process.

Consequently, these factors affect the texture of rice kernels. The information related to porosity and specific gravity, within other physical characteristics of the agricultural products, are of paramount importance for studies involving heat and mass transfer and air movement through the bulk grain (Ghadge \& Prasad, 2012). Rice grain quality is reported to be influenced by various physicochemical characteristics that determine the cooking behaviour and the cooked rice texture (Bocevska et al., 2009; Moongngarm et al., 2010).

Previous studies found that during cooking, the spaces between the rice grains are filled with water due to dripping water on the surface of the rice grains as the cooked rice grains are wet during cooking (Ramesh, 2000). Nowadays, people start to focus on consuming high-quality rice due to increasing health awareness. Thus, high-quality rice requirements will be substantially increased in market demand (Jiang et al., 2010).

The awareness of physicochemical characteristics of the selected rice (Malaysian \& Thai rice) is essentially vital during harvesting crops, transporting and dimensioning the storage process, manufacturing and operating various equipment applied in the main postharvest processing operation (Ghadge \& Prasad, 2012). Previously, research was performed on various brown rice and white rice (Chapagai et al., 2020; Sam Lum, 2017). Meanwhile, Thomas et al. (2013) reported differences in various brown rice from Thailand and Malaysia. 
However, research on white rice varieties' physicochemical properties is still limited, particularly between Malaysian and Thai rice. Therefore, it is essential to compare rice cultivars based on origin. Besides, the general physical properties can be used as general references for the grading, storage, and rice transportation in the rice industry.

Therefore, the present study's objective was to evaluate the difference in physicochemical properties of Malaysian and Thai rice cultivars.

\section{Materials and Methods}

\subsection{Sample Preparation}

The varieties of Malaysian rice used for this study were five kilograms of MR219, MR220CL, MR297, MR269, MR303, and MR309, obtained from a rice mill in Terengganu, Malaysia. The variety of Thai rice used was five kilograms of Thai jasmine rice, namely Khao Hom Mali from Royal Umbrella Thailand. These rice varieties were selected because they are commonly consumed and popular among both regions (Malaysia and Thailand). One kilogram of Malaysian and Thai rice was processed separately into powder by way of the grinding process (laboratory mill 120, Perten, Sweden). The samples were prepared by sieving Malaysian and Thai rice with the size of $2 \mathrm{~mm}$ before physicochemical measurement to get rid of foreign objects.

\subsection{Physical Properties}

\subsubsection{Dimension}

Rice properties were determined to include length, width, and thickness determined randomly; 20 rice kernel grains were used. A $0.1 \mathrm{~mm}$ accurate digital vernier calliper (Series500, Mitutoyo, Japan) was carried out in five replicates for rice kernel measurements. The values for length, width, and thickness of the 20 grains were recorded as mean \pm SD for each sample.

\subsubsection{Thousand kernel weight}

The 1000 weight from each cultivar was calculated randomly thrice. The 1000 kernel weight was determined separately using a digital balance (ER-120A, AND, Japan) with an accuracy of $0.0001 \mathrm{~g}$ (Ahmad et al., 2007).

\subsubsection{Length/width ratio}

Twenty grains of rice kernel were arranged lengthwise and then widthwise for the cumulative measurement of the ratio of length (l) and breadth (b) in millimetres. The $1 / \mathrm{b}$ ratio was calculated using the following equation 1 (Dela-Cruz \& Khush, 2000): 


$$
\mathrm{L} / \mathrm{B}=\frac{\text { average length of rice in } \mathrm{mm}}{\text { average breadth of rice in } \mathrm{mm}}
$$

\subsubsection{The bulk density}

The bulk density of rice kernels was calculated as mass per unit volume (Yadav et al., 2007). A $100 \mathrm{ml}$ beaker was filled with rice up to the $100 \mathrm{ml}$ sign, and the mass of rice grains was then weighed. The rice's weight was divided by the beaker's volume $(100 \mathrm{ml})$ (Fraser et al., 1978). This measurement was carried out in five replicates. The bulk density was calculated using the following equation 2 :

$$
\rho_{\mathrm{b}}=\frac{\mathrm{M}_{\mathrm{g}}}{\mathrm{V}_{\mathrm{b}}}
$$

\subsubsection{The actual density}

The actual density was calculated by filling the $100 \mathrm{ml}$ beaker with $50 \mathrm{ml}$ of distilled water and then placing a $3 \mathrm{~g}$ sample of rice into the respective beaker. The displaced water (volume of the grains) was recorded. The measurement was carried out in five replicates. The actual density was calculated using the following equation 3 :

$$
\rho_{\mathrm{t}}=\frac{\mathrm{M}_{\mathrm{gt}}}{\mathrm{V}_{\mathrm{dw}}}
$$

Where: $\rho_{\mathrm{t}}=$ true density $(\mathrm{g} / \mathrm{ml}) ; \mathrm{M}_{\mathrm{gt}}=$ mass of rice grain $(\mathrm{g}) ; \mathrm{V}_{\mathrm{dw}}=$ volume of displaced water $(\mathrm{ml})$

\subsubsection{The angle of repose}

The angle of repose indicates the nature of the pile formed by the material. It is an angle to horizontal at which material stands when piled. The apparatuses consist of a hollow cylinder and a plywood plate. The cylinder was filled with grains and inclined slowly, allowing the grains to fall out gradually until it was empty. The height and radius of the assumed slope were measured using the scale. The average reading of five replicates was recorded for accuracy (Firouzi \& Alizadeh, 2012). The angle of repose was calculated by using equation 4 : 


$$
\theta=\tan ^{-1}\left[\frac{2 H}{D}\right]
$$

Where: $\mathrm{H}=$ height of slope $(\mathrm{cm}) ; \mathrm{D}=$ the diameter of slope $(\mathrm{cm})$

\subsubsection{The aspect ratio, surface area, and volume}

The aspect ratio was calculated by using (Maduako and Faborode, 1990) equation 5:

$$
\mathrm{R}_{\mathrm{a}}=\frac{\mathrm{W}}{\mathrm{L}}
$$

Where: $\mathrm{w}=$ width of grain $(\mathrm{mm}) ; 1=$ length of grain $(\mathrm{mm})$

The surface area and volume were calculated using (Jain \& Bal, 1997) equations 6 and 7.

$$
\begin{gathered}
S=\frac{\pi \mathrm{BL}^{2}}{2 \mathrm{~L}-\mathrm{B}} \\
\mathrm{V}=0.25\left[\left(\frac{\pi}{6}\right) \mathrm{l}(\mathrm{w}+\mathrm{t})^{2}\right]
\end{gathered}
$$

Where: $\mathrm{S}=$ surface area $\left(\mathrm{mm}^{2}\right)$; w = width of grain $(\mathrm{mm}) ; \mathrm{b}=$ breadth of grain $(\mathrm{mm}) ; 1=$ length of grain $(\mathrm{mm}) ; \mathrm{t}=$ thickness of grain $(\mathrm{mm})$

\subsubsection{The sphericity}

Sphericity is defined as the ratio of the surface area of the sphere having the same volume as that of the grain to the grain's surface area. The sphericity was determined using equation 8 (Mohsenin, 1986).

$$
\emptyset=\frac{(\mathrm{LWT})^{1 / 3}}{\mathrm{~L}}
$$

Where: $\mathrm{w}=$ width of grain $(\mathrm{mm}) ; \mathrm{l}=$ length of grain $(\mathrm{mm}) ; \mathrm{t}=$ thickness of grain $(\mathrm{mm})$

\subsubsection{The porosity}

The porosity was computed by (Jain \& Bal, 1997) using equation 9.

$$
\varepsilon=\frac{\rho_{t}-\rho_{b}}{\rho_{t}} \times 100
$$

Where: $\varepsilon=$ porosity $(\%) ; \rho_{b}=$ bulk density $\left(\mathrm{kg} / \mathrm{m}^{3}\right) ; \rho_{t}=$ true density $\left(\mathrm{kg} / \mathrm{m}^{3}\right)$ 


\subsubsection{Grain hardness}

Grain hardness is the maximum peak force using a texture analyser (TA.XT Plus, Stable Micro System Corp., UK). All textural analyses were replicated five times per sample (Williams \& Phillips, 2000). A compression probe was set at $10 \mathrm{~mm}$ above the base. A onecycle compression was used with a pre-test of $1 \mathrm{~mm} / \mathrm{sec}$; a test of $2 \mathrm{~mm} / \mathrm{sec}$; a post-test of 10 $\mathrm{mm} / \mathrm{sec}$; and a trigger force of $5 \mathrm{~g}$. Hardness was the maximum force $(\mathrm{N})$ of the first compression and the linear section slope of the load-displacement curve (Odenigbo et al., 2014).

\subsubsection{Colour}

The colour parameters $\left(\mathrm{L}^{*}, \mathrm{a}^{*}, \mathrm{~b}^{*}\right)$ were determined using a colour meter (UltraScan Pro, HunterLab, USA). The colour results were reported in terms of the 5-dimensional values based on the CIE (Ahmad et al., 2016). The colour coordinates for the extent of lightness $\left(\mathrm{L}^{*}\right)$, redness-greenness $\left(\mathrm{a}^{*}\right)$, and yellowness-blueness $\left(\mathrm{b}^{*}\right)$. The notation of $\mathrm{L}^{*}$ is a light factor, $\mathrm{a}^{*}$ and $\mathrm{b}^{*}$ are the chromaticity coordinates, which are more closely defined as the human eye sensitivity to colour. $\mathrm{L}^{*}$ represents the difference between light $\left(\mathrm{L}^{*}=100\right)$ and dark $\left(L^{*}=0\right)$. Then, $a^{*}$ represents the difference between green $\left(-a^{*}\right)$ and red $\left(+a^{*}\right)$ while $b^{*}$ represents blue $\left(-b^{*}\right)$ and yellow $\left(+b^{*}\right)$. A complete quantitative measurement is needed in order to express colour in numerical dimensions and values, including attributes of colour such as hue (red, blue, green), saturation or chroma (intensity or strength of hue), and lightness (brightness or darkness) of the colour.

\subsection{Statistical Data Analysis}

The data obtained were represented as means with standard deviations of triplicate observations. An analysis of the Independent T-Test and the variance analyses were carried out to compare the significant difference at a 95\% confidence level using SPSS 16.0 (Fofana et al., 2011).

\section{Results and Discussions}

\subsection{Physical Properties of Malaysian Rice and Thai Rice}

The comparisons of the physical properties of Malaysian and Thai rice are summarised in Table 1. The length of raw Malaysian and Thai rice varied from 7.10 to 7.54 $\mathrm{mm}$, respectively. The Malaysian variety had a higher length $(7.54 \mathrm{~mm})$ than the Thai variety $(7.10 \mathrm{~mm})$. However, there were no significant differences $(p>0.05)$ in terms of length 
between Malaysian and Thai rice. According to Houston (1972), the length value of rice grains indicated as small has a maximum value $5.5 \mathrm{~mm}$; medium has a value of $5.51 \mathrm{~mm}$ to $6.6 \mathrm{~mm}$, and long has a value of $6.61 \mathrm{~mm}$ to $7.5 \mathrm{~mm}$. Thus, according to the present study, Malaysian and Thai rice belong to the long-grain rice variety. Similar to the results obtained by Megha et al. (2019), it was reported that the length value of Sonamasoori Low Polish (SMLP) is $7.17 \mathrm{~mm}$; Sonamasoori High Polish (SMHP) is $7.30 \mathrm{~mm}$; Rajmudi Unpolished (RUR) is $7.00 \mathrm{~mm}$, and Basmati (BR) is $11.2 \mathrm{~mm}$. All of which were classified as raw long grain rice.

Table 1. Physical properties of rice from different rice varieties.

\begin{tabular}{|c|c|c|c|}
\hline \multirow{2}{*}{ Physical Properties of rice } & \multirow{2}{*}{ Unit of measurement } & \multicolumn{2}{|c|}{ Cultivar } \\
\hline & & Malaysia & Thailand \\
\hline Length & $\mathrm{mm}$ & $7.54 \pm 0.33^{\mathrm{a}}$ & $7.10 \pm 0.29^{\mathrm{a}}$ \\
\hline Width & $\mathrm{mm}$ & $1.98 \pm 0.07^{\mathrm{a}}$ & $1.95 \pm 0.10^{\mathrm{a}}$ \\
\hline Thickness & $\mathrm{mm}$ & $1.66 \pm 0.07^{\mathrm{a}}$ & $1.53 \pm 0.11^{\mathrm{b}}$ \\
\hline Length/breadth ratio & $\mathrm{mm}$ & $4.16 \pm 0.20^{\mathrm{a}}$ & $4.11 \pm 0.20^{\mathrm{a}}$ \\
\hline Grain shape & - & Short /slender & Short /slender \\
\hline Surface area & $\mathrm{mm}^{2}$ & $24.41 \pm 1.38^{\mathrm{a}}$ & $22.00 \pm 1.76^{b}$ \\
\hline Bulk density & $\mathrm{g} / \mathrm{ml}$ & $0.80 \pm 0.04^{\mathrm{b}}$ & $0.86 \pm 0.00^{\mathrm{a}}$ \\
\hline True density & $\mathrm{g} / \mathrm{ml}$ & $1.55 \pm 0.09^{\mathrm{a}}$ & $1.50 \pm 0.01^{\mathrm{a}}$ \\
\hline Porosity & $\%$ & $48.15 \pm 4.35^{\mathrm{a}}$ & $42.78 \pm 0.18^{\mathrm{a}}$ \\
\hline Sphericity & $\%$ & $38.72 \pm 1.23^{\mathrm{a}}$ & $38.87 \pm 1.25^{\mathrm{a}}$ \\
\hline Aspect ratio & $\%$ & $26.29 \pm 1.47^{\mathrm{a}}$ & $27.31 \pm 1.55^{\mathrm{a}}$ \\
\hline Thousand weight kernels & $\mathrm{g}$ & $20.34 \pm 0.45^{\mathrm{a}}$ & $17.26 \pm 0.01^{b}$ \\
\hline Angle of repose & Degrees & $1.45 \pm 0.02^{\mathrm{a}}$ & $1.30 \pm 0.04^{\mathrm{a}}$ \\
\hline
\end{tabular}

The data were expressed as mean $\pm S D$, and each value is a mean of duplicate readings. Means followed by a different letter within the same row are significantly different $(p<0.05)$.

In terms of width, Malaysian and Thai raw rice varied from 1.95 to $1.98 \mathrm{~mm}$. The results present no significant variation $(p>0.05)$ in width between both varieties. The current results showed similar values with Mat Candu types $(1.97 \mathrm{~mm})$ reported by Husain (1984). The Malaysian variety showed a higher thickness value of $1.66 \mathrm{~mm}$, while the Thai variety showed a lower thickness value of $1.53 \mathrm{~mm}$. Meanwhile, the Malaysian variety exhibited a higher surface area value of $24.41 \mathrm{~mm}^{2}$, whereas the Thai variety indicated a lower surface area value of $22.00 \mathrm{~mm}^{2}$. Significant differences $(\mathrm{p}<0.05)$ between the Malaysian and Thai varieties were found in thickness and surface area. Besides, the short and slender grain shape can be indicated by the length/breadth ratio. In other words, a length to breadth ratio of above three is generally considered as slender (IRRI, 1980). The length/breadth (1/b) ratio and true density of Malaysian and Thai raw rice varied within the range of 4.11 to $4.16 \mathrm{~mm}$ and 1.50 to $1.55 \mathrm{~g} / \mathrm{ml}$, respectively. The length/breadth ratio and true density were not significantly 
different $(p>0.05)$ between the Malaysian and Thai varieties. Similar to other studies, which were observed by Thomas et al. (2013), it was reported that there were no significant differences $(p>0.05)$ in the respected aspect $(1 / \mathrm{b}$ ratio) for Basmati rice $(4.18 \mathrm{~mm})$.

Grain weight provides information about the size and density of the grains. Uniform grain weight is essential for consistent grain quality. Thus, bulk density is the material's weight, including the intergranular air space in unit volume (Bhattacharya, 2013). The current study shows significantly higher $(p<0.05)$ bulk density in Thai rice $(0.86 \mathrm{~g} / \mathrm{ml})$ compared to Malaysian rice $(0.80 \mathrm{~g} / \mathrm{ml})$. It indicates a more significant storage area or bin is required for storage compared to Malaysian rice. As reported previously by Pandey et al. (2016), this could be attributed to the greater length $(6.7 \mathrm{~mm})$ and thickness $(2.2 \mathrm{~mm})$ of the Jyoti rice variety as compared to the given rice cultivars. The higher bulk density of Shel Kew might be due to its grain's greater width $(2.91 \mathrm{~mm})$. The bulk density of grains is useful in designing silos and storage bins (Nalladurai et al., 2002). The larger the bulk density value, the bigger the size requirement for the silo and bin design despite their same weight. Bulk density is a vital parameter from a storage point of view required in bulk storage facilities like a silo. This property develops a vital role in silo wall pressure and grain flowing behaviors (Ghadge \& Prasad, 2012). The previous research done by Thomas et al. (2013) reported the results of bulk density from white (local), Bario rice, and Basmati rice were 0.81, 0.82, and $0.81 \mathrm{~g} / \mathrm{ml}$, respectively, were not significantly different from the current study.

Meanwhile, actual density is the measurement of the particles that make up powder or particulate solids. Cereal grain kernel densities have been of interest in breakage susceptibility and hardness studies. The present study showed no significant differences $(p<$ $0.05)$ were found in the actual density between the Malaysian $(1.55 \mathrm{~g} / \mathrm{ml})$ and Thai varieties $(1.50 \mathrm{~g} / \mathrm{ml})$. The thousand-grain weight delivers information about the size and density of the grain Megha et al. (2019). This property will affect the moisture retention and cooking characteristics significantly. Uniform grain weight is essential for consistent grain quality. The Malaysian variety ( $20.34 \mathrm{~g}$ ) holds the higher value of a thousand weight kernels, while the Thai variety (17.26 g) presents the lowest value. Previously, the Njavara variety (Medicinal red rice) was reported to have an average value of 1000 grain weight of $20.1 \mathrm{~g}$ (Elsy et al., 1992) and to range between $18.5 \mathrm{~g}$ to $30.0 \mathrm{~g}$ as given by Reddy (2000).

Additionally, aspect ratio distribution is essential to classify the varieties and exclude the off size in market grade (Varnamkhasti et al., 2008). Sphericity is defined as the ratio of the sphere's surface area having the same volume as that of the grain to the grain's surface 
area (Mohsenin, 1970). Sphericity is vital for designing storage in bulk for bins and silos. The sphericity values of raw, rough rice fall within the range of 0.32-1, as Mohsenin (1986) reported for most agricultural materials. Paddy grains with small sphericity will likely be more challenging to roll freely on a flat surface area (Sanusi et al., 2017). In the current study, Malaysian and Thai varieties present $38.72 \%$ and $38.87 \%$ sphericity, respectively. According to Sadeghi et al. (2010), Sorkheh and Sazandegi cultivars' sphericity was observed to range from 37 to $46 \%$ and 37 to $43 \%$, respectively. There were no significant variations between varieties. The angle of repose is another important physical property used to characterize the bulk of particulate foods: seeds, grains, flours, and grits. This angle is essential for the design of processing, storage, and conveying systems of particulate materials. Materials with a low angle of repose are highly flowable and can be transported using gravitational force or a little energy (Al-Hashemi \& Al-Amoudi, 2018). Therefore, the present study showed 1.45 degrees in the angle of repose of Malaysian rice, which was higher than Thai rice (1.30 degrees). Nevertheless, no significant variation was showed between both varieties.

In general, the current study shows no significant differences $(p>0.05)$ in terms of porosity, sphericity, aspect ratio, and angle of repose. However, significant variations ( $\mathrm{p}<$ 0.05 ) in terms of thickness, surface area, bulk density, and thousand weight of kernels were shown between both cultivars.

\subsection{Colour and Hardness of Malaysian and Thai Varieties}

Figure 1 presents the comparison of colour; L, a*, and $b^{*}$, respectively, between Malaysian and Thai cultivars. The colour of rice is often referred to as general appearance. The lightness and whiteness of cooked rice have a positive effect on consumer acceptance. However, most of the degree of colour change occurs during steaming or retorting (Hapsari et al., 2016; Xu et al., 2019). The results indicated that the Malaysian variety ( $\mathrm{L}=55.57)$ was lighter in colour than the Thai variety $(\mathrm{L}=55.44)$. The colour measurement showed that the rice kernel was whiter and brighter in colour. Furthermore, $a^{*}$ of Thai rice has a higher $\left(a^{*}=\right.$ $-0.44)$ green value than Malaysian rice $\left(a^{*}=-0.75\right)$. Moreover, $b^{*}$ showed that Thai rice $\left(b^{*}\right.$ $=5.86)$ has a higher yellow value than Malaysian rice $\left(b^{*}=4.96\right)$. 


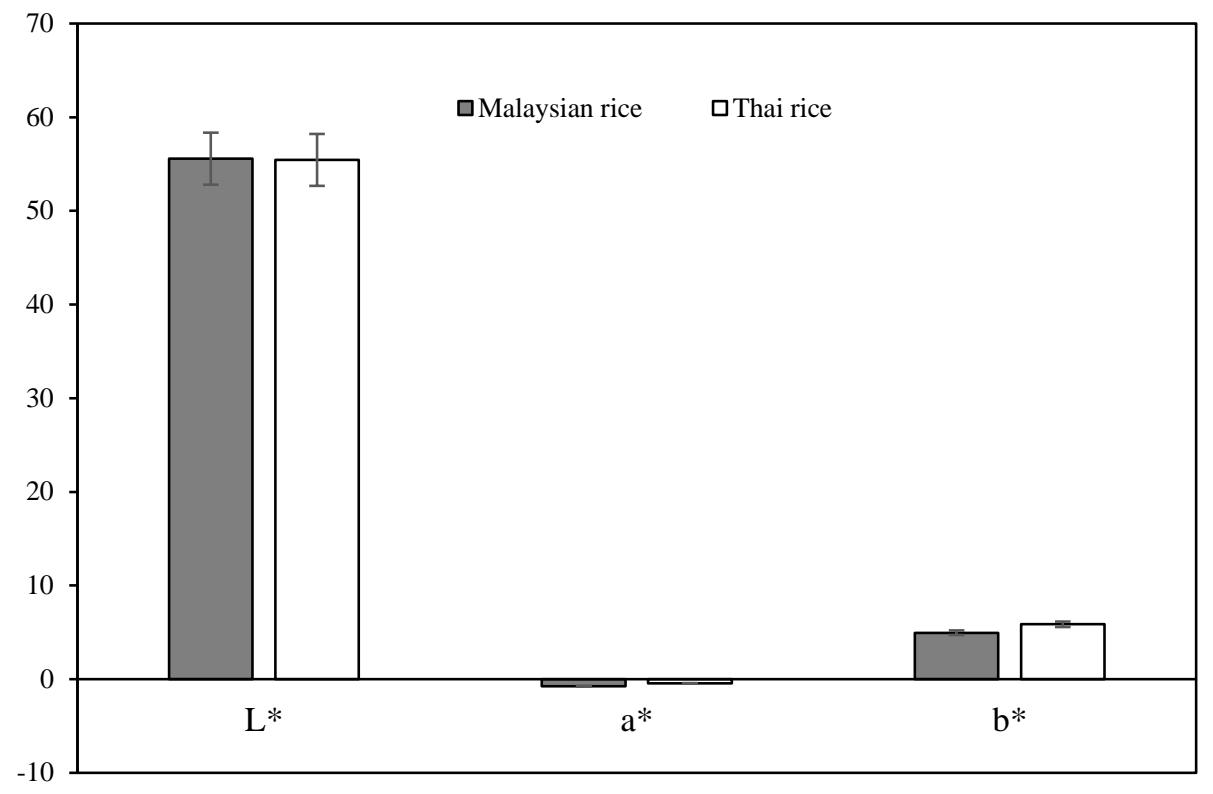

Figure 1. Comparisons of colour were indicated by lightness $\left(\mathrm{L}^{*}\right), \mathrm{a}^{*}$ and, $\mathrm{b}^{*}$ of rice kernel between Malaysia and Thailand

Besides, Figure 2 presents the comparison of hardness between Malaysian and Thai cultivars. The result signifies that the rice variety from Malaysia showed a lesser value of $9.83 \pm 3.57 \mathrm{~kg}$ than Thailand, which showed a value of $11.76 \pm 2.15 \mathrm{~kg}$. In general, Thai rice cultivars display significantly greater $(p<0.05)$ hardness compared to Malaysian rice cultivars. The difference in variety in rice grains' hardness is due to the difference in the compact arrangement between rice cultivars of starch granules. The Thai variety may be hard due to its higher content of the bran layer, while lower hardness in Malaysian rice is assumed due to the thin bran layer's likely presence (Chapagai et al., 2020). Besides, the lower hardness level is preferred as it will affect the cooking properties. Shafutri et al. (2016) responded that the cooked rice with a high hardness value was harder than a low value. 


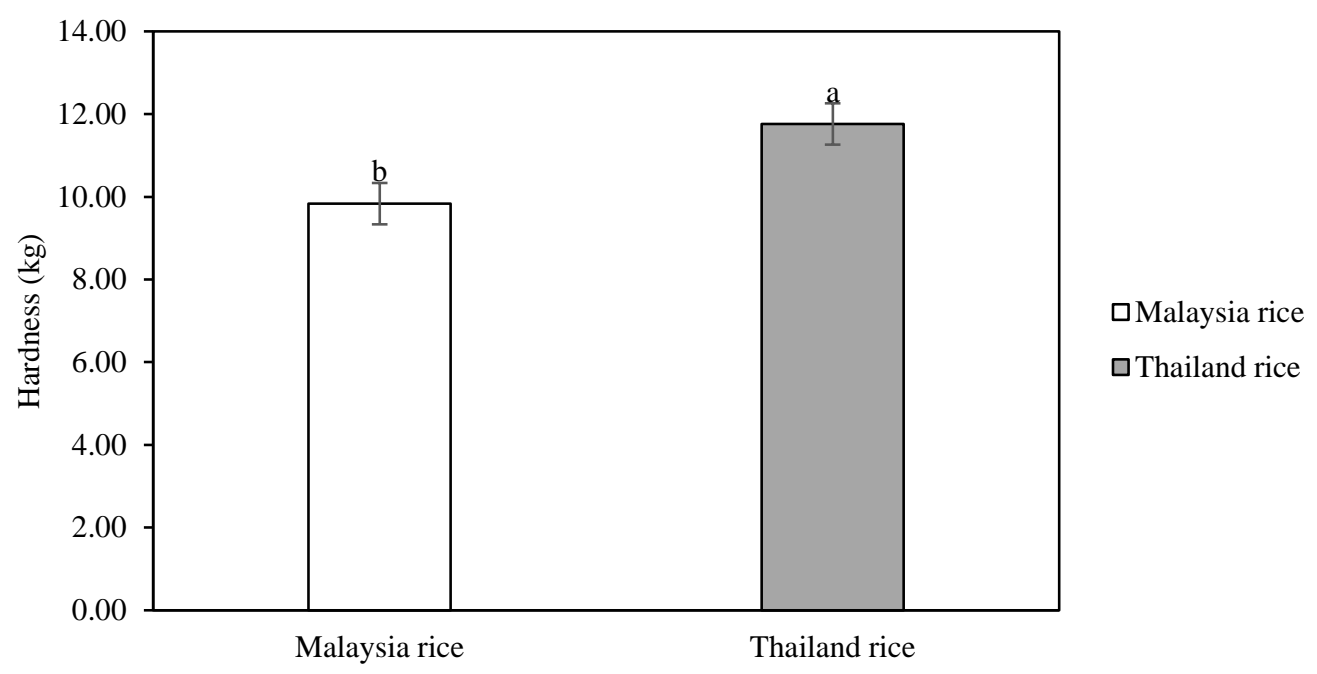

Figure 2. Comparison of the hardness of rice kernel between Malaysia and Thailand.

\section{Conclusion}

In general, the investigation has presented that the physical dimensions (thickness, surface area, bulk density, thousand weight kernels, colour ( $\left.\mathrm{a}^{*}\right)$ and hardness) of Malaysian rice and Thai rice vary significantly. The current study's significant findings reflected that Malaysia rice had a thickness of $1.66 \mathrm{~mm}$, surface area of $24.41 \mathrm{~mm}^{2}$, bulk density $0.80 \mathrm{~g} / \mathrm{ml}$, thousand weight kernels of $20.34 \mathrm{~g}$, color ( $\mathrm{a}^{*}$ ) of -0.44 , and hardness of $9.83 \mathrm{~kg}$. The Thai rice had a thickness of $1.53 \mathrm{~mm}$, surface area of $22.00 \mathrm{~mm}^{2}$, bulk density $0.86 \mathrm{~g} / \mathrm{ml}$, thousand weight kernels of $17.26 \mathrm{~g}$, color $\left(\mathrm{a}^{*}\right)$ of -0.75 , and hardness of $11.76 \mathrm{~kg}$. The differences in their physical parameters could affect consumers' selection as they have their rice quality preferences. In conclusion, Malaysian rice possessed higher consumer preferences in lighter colours with lower bulk density and hardness value.

Funding: The authors express their gratitude to the Farmers Organisation (Langkawi) and Farmers Organisation Authority for their support to this research, Universiti Putra Malaysia for providing financial and technical support to conduct this research, and the Faculty of Engineering and Agro-industry at Maejo University for the financial support for the allowance.

Acknowledgments: The authors express their gratitude to Universiti Putra Malaysia for providing financial and technical support to conduct this research.

Conflicts of Interest: The authors declare no conflict of interest in the study.

\section{References}

Ahmad, R. Hashifah, M. A., Shariffah Norin, S. A. (2007). The physico-chemical properties and nutritional composition of rice bran produced at different milling degrees of rice. Journal of Tropical Agriculture and Food Science, 35, 99-105. 
Ahmad, R., Khalid, K.H., Abdullah, S.N.S. (2016). Characteristics of local rice flour (MR 220) produced by wet and dry milling methods. Journal of Tropical Agriculture and Food Science, 44 (1), 147-155.

Al-Hashemi, H. M. B. \& Al-Amoudi, O. S. B. (2018). A review on the angle of repose of granular materials. Powder Technology, 330, 397-417. doi:https://doi.org/10.1016/j.powtec.2018.02.003

Bhattacharya, K. R. (2013). Analysis of rice quality in Rice Quality: A guide to rice properties and analysis. Woodhead Publishing Series in Food Science, Technology and Nutrition, 13, 431-530. doi: https://doi.org/10.1533/9780857092793.431

Chapagai, M. K., Wan Rosli, W. I., Karilla, T., et al. (2020). Variety difference of physicochemical and cooking properties of selected brown rice from Thailand and Malaysia. Food Research, 4(3), 630-635. https://doi.org/10.26656/fr.2017.4(3).305

Dela-Cruz, N. \& Khush, G. S. (2000). Rice grain quality evaluation procedures in Aromatic rices. Published by Mohan Primlani, Oxford \& IBH Publishing Co. Pvt. Ltd., New Delhi, 3, 15-28.

Firouzi, S. \& Alizadeh, M. (2012). Effect of moisture content on selected physical characteristics of cowpea seed (Vignaunguiculata L. Walp). Annals Biological Research, 3(7), 3583-3590.

Fofana, M., John, T. M., Koichi, F., et al. (2011). Rice grain quality: A comparison of imported varieties, local varieties with new varieties adopted in Benin. Food Control, 22(12), 1821-1825. doi: https://doi.org/10.1016/j.foodcont.2011.04.016

Fraser, B. M., Verma, S. S., Muir, W. E. (1978). Some physical properties of fababeans. Journal of Agricultural Engineering Research, 22(1), 53-57. doi:https://doi.org/10.1016/0021-8634(78)90079-3

Ghadge, P. N. \& Prasad, K. (2012). Some Physical Properties of Rice Kernels: Variety PR-106. J Food Process Technol, 3(8). doi: 10.4172/2157-7110.1000175

Hapsari, A., Kim, S., Eun, J. (2016). Physical characteristics of parboiled Korean glutinous rice (Olbyeossal) using a modified method. LWT - Food Science and Technology, 68, 499-505. doi:https://doi.org/10.1016/j.lwt.2015.12.066

Husain, A. N. (1984). Quality parameters for Malaysian rice varieties. MARDI Research Bulletin, 320-332

Houston, D. F. (1972). Rice chemistry and technology. The American Association of Cereal Chemistry. St. Paul, MN, USA

IRRI, International Rice Research Institute. (1980). Descriptors for rice Oryza sativa L. Los Banos, Laguna, Philippines, 25-38

Jain, R. K. \& Bal, S. (1997). Properties of pearl millet. Journal of Agricultural Engineering Research, 66(2), 85-91. doi: https://doi.org/10.1006/jaer.1996.0119

Jiang, N., Gao, Y., Zhou, J., et al. (2010). The quantized characterization of cooked rice hardness and research on the automatic measurement technology. Engineering, 2, 97-102. doi: 10.4236/eng.2010.22013 
Maduako, J. N. \& Faborode, M. O. (1990). Some physical properties of cocoa pods in relation to primary processing. Ife Journal of Technology, 2, 1-7.

Megha C. P., Ramesh, D., Prakash, J. (2019). Physico-chemical and cooking properties of selected rice varieties. Acta Scientific Nutritional Health, 3(3), 23-30

Mohsenin, N. N. (1986). Physical properties of plant and animal materials (2nd ed.). Gordon and Breach Science Publishers, New York.

Mohsenin, N. N. (1970). Physical properties of plant and animal materials: structure, physical characteristics and mechanical properties. New York, USA: Gordon and Breach Science Publishers Inc, 841-881

Nalladurai, K., Alagusundaram, K., Gayathri, P. (2002). PH-Postharvest Technology: Airflow resistance of paddy and its by-products. Biosystems Engineering, 831(1), 67-75. doi: https://doi.org/10.1006/bioe.2002.0091

Odenigbo, A. M., Ngadi, M., Ejebe, C., et al. (2014). Physicochemical, cooking characteristics and textural properties of TOX 3145 milled rice. Journal of Food Research, 3(2), 82-90.doi: 10.5539/jfr.v3n2p82

Pandey, S, Asha M.R., Jayadep, A (2016). Changes in physical, cooking, textural properties and crystallinity upon iron fortification of red rice (Jyothi). J Food Sci Technol. 53(2):1014-1024. doi: 10.1007/s13197015-2130-7.

Ramesh, M. N. (2000). Effect of cooking and drying on the thermal conductivity of rice. International Journal of Food Properties, 3(1), 77-92. doi: https://doi.org/10.1080/10942910009524617

Reddy, G. S. 2000. Characterisation and evaluation of the rice (Oryza sativa L.) cultivar Njavara M. Sc (Ag.) Thesis, Kerala Agricultural University, Thrissur. Pp. 137

Saleh, M. \& Meullenet, J-F. (2015). Cooked rice texture and rice flour pasting properties. Journal of Food Science and Technology, 52(3), 1602-1609. doi: https://doi.org/10.1007/s13197-013-1180-y

Sadeghi, M., Araghi, H. A., Hemmat, A. (2010). Physico-mechanical properties of rough rice (Oryza sativa L.) grain as affected by variety and moisture content. Agricultural Engineering International: CIGR Journal, 12(3), 129-136.

Sam Lum, M. (2017). Physicochemical Characteristics of Different Rice Varieties Found in Sabah, Malaysia. Transactions on Science and Technology, 4(2), 68-75. http://transectscience.org/

Sanusi, M., Akinoso, R., Danbaba, N. (2017). Evaluation of physical, milling and cooking properties of four new rice (Oryza sativa L.) varieties in Nigeria. International Journal of Food Studies, 6(2), 245-256. doi: https://doi.org/10.7455/ijfs/6.2.2017.a10

Singh, N., Sodhi, N.S., Kaur, M., et al. (2003). Physico-chemical, morphological, thermal, cooking and textural properties of chalky and translucent rice kernels. Food Chemistry, 82(3), 433-439. doi: https://doi.org/10.1016/S0308-8146(03)00007-4 
Thomas, R., Wan Nadiah, W. A., Bhat, R. (2013). Physiochemical properties, proximate composition, and cooking qualities of locally grown and imported rice varieties marketed in Penang, Malaysia. International Food Research Journal, 20(3), 1679-1685

Varnamkhasti, M. G., Mobli, H., Jafari, A., et al. (2008). Some physical properties of rough rice (oryza sativa 1.) grain. Journal of Cereal Science, 47(3), 496-501. doi: https://doi.org/10.1016/j.jcs.2007.05.014

Williams, P. A. \& Phillips, G.O. (2000). Gums and stabilisers for the food industry 10. Woodhead Publishing Limited, Ireland.

Xu, D., Hong, Y., Gu, Z., et al. (2019). Effect of high pressure steam on the eating quality of cooked rice. $L W T$ Food Sience and Technology, 104, 100-108. doi: https://doi.org/10.1016/j.1wt.2019.01.043

Yadav, R. B., Khatkar, B. S., Yadav, B. S. (2007). Morphological, physicochemical and cooking properties of some Indian rice (Oryza sativa L.) cultivars. Journal of Agricultural Technology, 203-210. 